\title{
BMJ Asthma mortality in Australia in the Open 21st century: a case series analysis
}

\author{
Dianne P Goeman, ${ }^{1}$ Michael J Abramson, ${ }^{2}$ Edwina A McCarthy, ${ }^{3}$ \\ Celia M Zubrinich, ${ }^{3}$ Jo A Douglass ${ }^{4}$
}

To cite: Goeman DP, Abramson MJ, McCarthy EA, et al. Asthma mortality in Australia in the 21 st century: a case series analysis. BMJ Open 2013;3:e002539. doi:10.1136/bmjopen-2012002539

\section{- Prepublication history for this paper are available online. To view these files please visit the journal online (http://dx.doi.org/10.1136/ bmjopen-2012-002539).}

Received 30 December 2012 Revised 2 March 2013 Accepted 12 March 2013

This final article is available for use under the terms of the Creative Commons Attribution Non-Commercial 2.0 Licence; see http://bmjopen.bmj.com
For numbered affiliations see end of article.

\footnotetext{
Correspondence to Dr Dianne P Goeman, dgoeman@rdns.com.au
}

\section{ABSTRACT}

Objective: As previous asthma mortality studies were undertaken between 1986 and 1997, and treatments have evolved since that time, in order to direct future asthma interventions, we investigated the reasons for asthma deaths between 2005 and 2009.

Design: We undertook a case series analysis by searching the National Coroners' Information System using the most recent International Classification of Diseases- 10 codes J45 and J46 and the keyword 'asthma' as the underlying cause of death.

Setting: Records for 283 cases aged 70 years and under were retrieved from each Australian state and territory. Coroner's findings, autopsy, toxicology and police reports were reviewed to determine: if the team agreed the death was due to asthma and whether the death was preventable or modifiable factors existed? Owing to the likelihood of comorbidities or alternative diagnoses contributing to deaths in those over 70 years of age, this group was excluded.

Results: Examination of available data in those aged under 70 years identified risk factors associated with asthma death. These included physical barriers (rural and remote location, institutionalised care), psychosocial issues (social disengagement, mental illness, living alone, being unemployed), smoking, drug and alcohol dependence, allergies, respiratory tract infections, inadequate treatment and delay in seeking help.

Conclusions: Our study provides a current assessment of death from asthma across Australia. Further reductions in the rate of asthma deaths will require interventions targeted at the personal, practice and policy levels. Asthma-related health literacy needs to be improved especially among those with episodic asthma. Reforms are also needed to address inequity in healthcare delivery to 'reach the unreached'. Our study points to the dangers associated with smoking, drug and alcohol use and the consequences of delay in seeking care among those with asthma.

\section{BACKGROUND}

The most recent record of Australian asthma deaths, in 2010, recorded asthma as the underlying cause for 416 deaths. ${ }^{1}$ This is an increase on the 385 deaths recorded in $2007^{1}$ but a decrease on asthma deaths in

\section{ARTICLE SUMMARY}

\section{Article focus}

- Despite classification as a National Health Priority and the introduction of National Asthma Guidelines in the 1990s, asthma is associated with a substantial impact on the community and asthma deaths remain high by international comparators.

- Previous asthma mortality studies were undertaken between 1986 and 1997; asthma treatments have evolved since this time.

- In order to direct future asthma interventions, we investigated reasons for asthma deaths between 2005 and 2009.

\section{Key messages}

- Our study is a current assessment of death from asthma across Australia.

- Asthma deaths in Australia are associated with health inequalities, drug and alcohol use, psychosocial issues, poor health literacy and social isolation.

- There is an urgent need for interventions that 'reach the unreached' by targeting practice and policy in addition to interventions at a personal level to improve asthma-related health literacy.

2008, where asthma was the underlying cause for 449 deaths. $^{1}$ This rate of 1.6/100 000 people is high by international comparison. ${ }^{2}$

Previous asthma mortality studies were undertaken in Victoria and South Australia during the late 1980 s and the 1990s. ${ }^{3-6}$ As the pattern of asthma deaths may have changed over the last decade and more effective medications are now available, we undertook a study of deaths between 2005 and 2009 to discover the current circumstances surrounding the deaths and to identify potential interventions.

\section{METHODS}

\section{Data collection}

As recently introduced privacy laws prevent the use of Death registries in Australia for the purpose of identifying individuals who 


\section{ARTICLE SUMMARY}

\section{Strengths and limitations of this study}

- Our retrospective study of asthma deaths between 2005 and 2009 is the most recent study of asthma deaths undertaken in Australia for nearly two decades, and the first to report asthma deaths across Australia. We confirmed that 243/283 deaths were due to asthma rather than having asthma as a comorbidity when another immediate cause of death existed. We identified preventable or modifiable factors in $70 \%$ of these deaths.

- Recently introduced privacy laws prevent the use of death registries in Australia for the purpose of identifying individuals who have died. Our study therefore differs from the previous mortality studies in that we used NCIS to identify asthma deaths. The limitations of our data include the examination of only those asthma deaths that were reported to the Coroner. The Coroner investigates 'reportable' deaths, that is, a death that is 'unexpected', 'unnatural', 'violent' or the death of those 'in care' at the time of death. Thus, cases are likely to be biased towards younger people or those institutionalised at the time of death. Anticipated deaths from asthma would not have been reported, and as a consequence, our study may underestimate this group. As the cause of death analysis focuses on only one underlying cause rather than multiple causes of death, the overall contribution of asthma to adult deaths in Australia is also likely to be underestimated.

have died, we examined cases of asthma death reported to the Coroner and recorded on the National Coroners Information System (NCIS). The Coroner investigates 'reportable' deaths, that is, a death, that is, 'unexpected', 'unnatural', 'violent' or the death of those 'in care' at the time of death.

Usually a police officer or a medical practitioner will notify the Coroner of any death that may be 'reportable'. However, any person may notify the Coroner if they believe that a reportable death has occurred. The role of the Coroner is to investigate the circumstances surrounding all 'Reportable deaths'.

At the conclusion of every investigation, it is the task of the Coroner to prepare a written finding to establish wherever possible: the identity of the deceased; the circumstances surrounding the death; the cause of death; and the particulars needed to register the death. An autopsy, undertaken by a forensic pathologist, can help explain the cause of death and is part of the coronial investigation into 'reportable' deaths. As the next of kin has a legal right to file an objection to an autopsy being conducted, the Coroner will take into consideration any such objection, and therefore an autopsy is not always carried out. Once the pathologist has all the results of the tests, a detailed report is prepared for the Coroner, which outlines the medical findings and conclusions. The Coroner takes this information into account when making a finding. Once the Coroner has made a finding, the case is considered 'closed' and coded according to International Classification of Disease for the underlying cause of death.

We ascertained the number of asthma deaths recorded in each state and territory in Australia, between 2005 and 2009, using available Australian Bureau of Statistics ${ }^{1}$ and Australian Institute of Health and Welfare data (see tables 1 and 2). ${ }^{7}$

We then undertook a retrospective case series analysis by searching the NCIS $^{8}$ using the most recent International Classification of Diseases (ICD-10) codes $\mathrm{J} 45$ and $\mathrm{J} 46^{9}$ and the keyword 'asthma' as the underlying cause of death. The Coroner's findings, autopsy, toxicology and police reports were reviewed to determine: if the team agreed that death was due to asthma and whether it was preventable or modifiable factors existed. Cases of asthma deaths in those under 70 years of age that were deemed to be due to asthma were included in our analysis. The team consisted of three respiratory physicians, a medical sociologist and a research officer.

Demographic comorbidities, medication use and smoking history information were noted from available police, toxicology, autopsy reports or the Coroner's findings. Preventable deaths were assessed on the basis of available details and consensus clinical judgement if different or specific actions had been taken and the death was likely to have been avoided. Modifiable factors

Table 1 Asthma deaths/rate per 100000 in Australia by age from 2005 to 2008

\begin{tabular}{|c|c|c|c|c|c|}
\hline Age & 2005 & 2006 & 2007 & 2008 & Overall \\
\hline 0-9 & 3 & 0 & 1 & 7 & 11 \\
\hline $10-19$ & 4 & 5 & 4 & 4 & 17 \\
\hline 20-29 & 14 & 11 & 16 & 9 & 50 \\
\hline 30-39 & 11 & 8 & 15 & 23 & 57 \\
\hline $40-49$ & 34 & 22 & 24 & 25 & 105 \\
\hline $50-59$ & 22 & 27 & 32 & 36 & 117 \\
\hline $60-69$ & 39 & 56 & 52 & 53 & 200 \\
\hline Total under 70 years & 127 & 129 & 144 & 157 & 557 \\
\hline $70-79$ & 47 & 68 & 53 & 61 & 229 \\
\hline $80-89$ & 144 & 205 & 188 & 229 & 766 \\
\hline Total 70 years and over & 191 & 273 & 241 & 290 & 995 \\
\hline Overall deaths and rate per $100000 /$ year & $318(1.5)$ & 402(1.8) & $385(1.7)$ & 449 (1.9) & 1552 \\
\hline
\end{tabular}


Table 2 Cases deemed to be asthma deaths examined from National Coroners Information System between 2005 and 2008 by age, gender and Socioeconomic Index For Areas (SEIFA)

\begin{tabular}{|c|c|c|c|c|c|}
\hline & 2005 & 2006 & 2007 & 2008 & Overall \\
\hline \multicolumn{6}{|l|}{ Age } \\
\hline $0-9$ & 2 & 0 & 1 & 6 & 9 \\
\hline $10-19$ & 3 & 3 & 2 & 4 & 12 \\
\hline $20-29$ & 9 & 8 & 12 & 2 & 31 \\
\hline 30-39 & 8 & 5 & 9 & 13 & 35 \\
\hline $40-49$ & 20 & 13 & 11 & 10 & 54 \\
\hline $50-59$ & 12 & 18 & 8 & 15 & 53 \\
\hline $60-69$ & 16 & 11 & 12 & 9 & 48 \\
\hline Total under 70 & 70 & 58 & 56 & 59 & 243 \\
\hline \multicolumn{6}{|l|}{ Gender } \\
\hline Male & 39 & 25 & 28 & 34 & 126 \\
\hline Female & 31 & 33 & 28 & 25 & 117 \\
\hline Total & 70 & 58 & 56 & 59 & 243 \\
\hline \multicolumn{6}{|l|}{ SEIFA } \\
\hline-1000 & $18 \%(45)$ & $14 \%(33)$ & $16 \%(38)$ & $17 \%(41)$ & $65 \%(157)$ \\
\hline+1000 & $10 \%(24)$ & $10 \%(25)$ & $7 \%(18)$ & $7 \%(18)$ & $35 \%(85)$ \\
\hline Missing & 1 & & & & \\
\hline Total & 70 & 58 & 56 & 59 & 243 \\
\hline
\end{tabular}

associated with death were factors amenable to change and may have contributed to the fatal outcome.

\section{Data analysis}

Socioeconomic status

Socioeconomic status was determined using ABS-Socioeconomic Indices For Areas (SEIFA), a continuum of advantage (high values) to disadvantage (low values). SEIFA used a broad definition of relative socioeconomic disadvantage in terms of people's access to material and social resources, and their ability to participate in society. Advantage/disadvantage classifications were derived from Census variables related to low income, low educational attainment, unemployment, dwellings without motor vehicles, high household income and tertiary education. ${ }^{10}$ SEIFA index scores were standardised to a mean of 1000 . A lower score indicated an area of relative disadvantage compared to an area with a score higher than 1000 .

\section{Exclusion criteria}

Owing to the likelihood of comorbidities or alternative diagnoses contributing to deaths in those over 70 years of age, this group was excluded.

\section{Statistical analysis}

Descriptive analysis was performed using SPSS V.20 (Statistical Package for Social Sciences, IBM Corporation 2011). $\chi^{2}$ was used to test differences of proportions.

\section{Ethics}

The Alfred Hospital Human Research and the Department of Justice Ethics Committees approved the study.

\section{RESULTS}

\section{Data}

The Department of Justice granted permission to access data for closed cases, that is, cases where the Coroner had made a finding across Australia. West Australian data (26 cases) were restricted to non-identifying demographic information. Of the 557 asthma deaths in those under 70 years of age between 2005 and 2009, we retrieved $283(51 \%)$ cases (see figure 1 ).

Sufficient information was available (Coroner's findings, autopsy, toxicology and police reports) to determine the main cause of death as asthma in 243 of the 283 cases. An autopsy had been conducted in 209(86\%)

Figure 1 Flow diagram of cases examined.

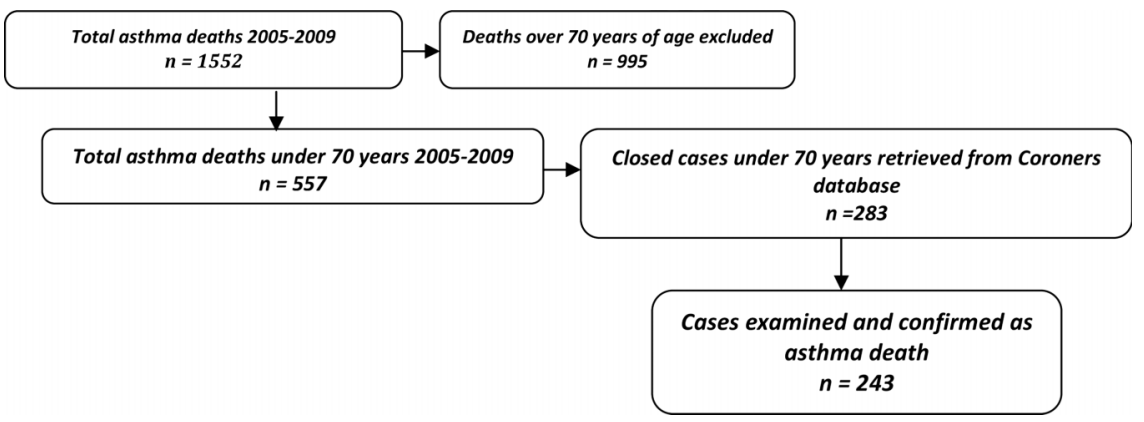


cases and toxicological analysis in 159 (56\%) cases (84/159 were accessible on NCIS). Tables 1 and 2 provide a breakdown of the overall death rate, age, gender and SEIFA classification of the cases examined.

\section{Preventable/modifiable deaths}

Preventable or modifiable factors were identified in $70 \%$ $(169 / 243)$ of the cases examined. There was insufficient information to determine whether $28 \%$ (70) deaths were preventable or modifiable. Four cases were deemed as not preventable (see table 3 below).

\section{Case characteristics}

A slight majority, 126/243(52\%) deaths were male. The age range of cases was between 2 and 70 years of age with a mean $( \pm \mathrm{SD})$ age $44 \pm 17$ years. There was no association between age $\left(\chi^{2}=42.8, p=0.9\right)$ or gender $\left(\chi^{2}=0.017\right.$, $\mathrm{p}=0.9)$ and whether the asthma death was considered preventable or not.

\section{Location of death}

The majority of deaths, $145 / 243(60 \%)$, occurred at home. For seven cases, home was a caravan. Twenty $(8 \%)$ deaths occurred either at a hospital or a general practitioner's Clinic, and 13 (4\%) on the way to hospital. Eleven deaths $(4 \%)$ occurred in public places (airport, school, bus stop, restaurant, street, workplace, camping ground). Six deaths (2\%) occurred in residential institutions. The location of death was not available for $47(19 \%)$ cases.

\section{Socioeconomic status}

One hundred and fifty-seven $(65 \%)$ cases lived in areas classified as disadvantaged. The mean $( \pm \mathrm{SD})$ SEIFA advantage/disadvantage classification of cases was $980 \pm 74$. Of the 169 preventable or modifiable deaths, $106(62 \%)$ were classified as disadvantaged. A slightly higher number of preventable deaths, 67\% (106/157), occurred in those living in disadvantaged areas.

Only $91(37 \%)$ of the deceased persons were employed at the time of death. Seventeen $(7 \%)$ were women undertaking home duties, $61(25 \%)$ were unemployed, 29 $(12 \%)$ were retired, $19(8 \%)$ were students and $2(1 \%)$ were children under 5 years of age. There was no employment status listed for $24(10 \%)$ cases.

\section{Psychosocial issues}

Psychosocial factors were identified in 106(49\%) cases. These factors included living alone, social disengagement and mental health issues. Mental illnesses included bipolar disorder, depression, schizophrenia, personality or compulsive obsessive disorders and anxiety.

\section{Drug and alcohol use/abuse}

Drug and alcohol abuse was identified as a factor contributing to death in $83(34 \%)$ cases. Recreational/ illicit drugs included opiates, methamphetamines, methadone, cannabis and alcohol (see table 4). Sixty $(25 \%)$ case records identified the deceased as a smoker.

\section{Inadequate treatment/management}

Preventer medication ownership was recorded in $28 \%$ of cases. As information on asthma medicines was not routinely recorded, conclusions on under-or-overuse of therapy or financial barriers cannot be drawn. References to reliever/rescue medication use included ownership of a symptom modifier without an accompanying preventer, evidence of expired or empty rescue medication, inhalers/nebules strewn about the room and nebuliser machines still running.

Inadequate treatment was recorded in $43(18 \%)$ cases. Inadequate treatment was not only related to poor selfmanagement, but also included deficits in the provision

Table 3 Characteristics of preventable/modifiable deaths

\begin{tabular}{|c|c|c|c|}
\hline & $\begin{array}{l}\text { Preventable or } \\
\text { modifiable factors } \\
(n=169)\end{array}$ & $\begin{array}{l}\text { Non-preventable or } \\
\text { modifiable factors }(n=4)\end{array}$ & $\begin{array}{l}\text { Insufficient data to } \\
\text { determine if death was } \\
\text { preventable }(n=70)\end{array}$ \\
\hline Age (Mean $\pm S D)$ & $43 \pm 17$ & $57 \pm 10$ & $46 \pm 17$ \\
\hline Gender & $90 \mathrm{M} 79 \mathrm{~F}$ & $2 \mathrm{M} 2 \mathrm{~F}$ & $34 \mathrm{M} 36 \mathrm{~F}$ \\
\hline SEIFA & $985 \pm 74$ & $980 \pm 98$ & $968 \pm 70$ \\
\hline \multicolumn{4}{|l|}{ Location of death } \\
\hline Home/friends $(n=145)$ & $122(84 \%)$ & $4(3 \%)$ & $19(13 \%)$ \\
\hline Hospital/GP $(n=20)$ & $14(70 \%)$ & 0 & $6(30 \%)$ \\
\hline Ambulance/on way to hospital $(n=13)$ & $12(92 \%)$ & 0 & $1(8 \%)$ \\
\hline Public place $(n=11)$ & $11(100 \%)$ & 0 & 0 \\
\hline Residential care $(n=6)$ & $3(50 \%)$ & 0 & $3(50 \%)$ \\
\hline Missing $(n=47)$ & $8(17 \%)$ & 0 & $39(83 \%)$ \\
\hline Psychosocial issues $(n=106)$ & $93(88 \%)$ & $2(2 \%)$ & $11(10 \%)$ \\
\hline Drug and alcohol abuse $(n=83)$ & $78(85 \%)$ & $1(1 \%)$ & $4(4 \%)$ \\
\hline Delay in seeking help $(n=63)$ & $57(89 \%)$ & & $6(9 \%)$ \\
\hline Respiratory tract infection $(n=39)$ & $31(80 \%)$ & $3(7 \%)$ & $5(13 \%)$ \\
\hline Sudden onset $(n=111)$ & $90(81 \%)$ & & $21(19 \%)$ \\
\hline
\end{tabular}


Table 4 Toxicology results.

\begin{tabular}{|c|c|c|c|}
\hline Drug & $\mathbf{n}$ & Mean concentration \pm SD & Normal values* \\
\hline Alcohol-blood ethanol & 32 & $0.09 \pm 0.09 \mathrm{~g} / 100 \mathrm{ml}$ & $<0.05 \mathrm{~g} / 100 \mathrm{ml}$ \\
\hline Opiates/morphine/pethidine & 8 & $6 \pm 7 \mathrm{mg} / \mathrm{l}$ & $0.01-0.1 \mathrm{mg} / \mathrm{l}, 0.1-0.8 \mathrm{mg} / \mathrm{l}$ \\
\hline Methadone & 7 & $0.8 \pm 0.3 \mathrm{mg} / \mathrm{l}$ & $0.1-0.5 \mathrm{mg} / \mathrm{l}$ \\
\hline Amphetamine $†$ & 7 & $0.15 \pm 0.15 \mathrm{mg} / \mathrm{l}$ & $0.02-0.1 \mathrm{mg} / \mathrm{l}$ \\
\hline Tetrahydrocannabinol $\ddagger$ & 15 & $3 \pm 4.9 \mathrm{mg} / \mathrm{l}$ & $0.005-0.01 \mathrm{mg} / \mathrm{l}$ \\
\hline Ketamine & 3 & $0.1,0.7,2.0 \mathrm{mg} / \mathrm{l}$ & $1-6 \mathrm{mg} / \mathrm{l}$ \\
\hline Caffeine & 1 & $10 \mathrm{mg} / \mathrm{l}$ & $4-10 \mathrm{mg} / \mathrm{l}$ \\
\hline \multicolumn{4}{|c|}{$\begin{array}{l}\text { Critical Care } 2012 ; 16: \mathrm{R} 136 \text { doi: } 10.1186 / \mathrm{cc} 11441 \text {. } \\
\text { Toxicology examination was performed in } 159 \text { cases; } 84 \text { of these reports were accessible. } \\
\text { Toxicology reports were not available for the } 26 \text { West Australian cases or } 49 \text { cases in other states. } \\
\text { *Therapeutic ('normal'), toxic and comatose-fatal blood-plasma concentrations (mg/l) in man. } \\
\text { †Amphetamine and/or methamphetamine. } \\
\text { †Tetrahydrocannabinol. }\end{array}$} \\
\hline
\end{tabular}

of asthma care. It was not possible, in most cases, to determine written action plan ownership from this data set. Unfamiliarity with the individual's asthma or inexperience with provision of asthma care by both health professionals and carers was a contributing factor to several deaths that occurred in the hospital, home and institutional settings.

\section{Physical barriers}

Rural or remote areas were the setting for 109(45\%) deaths attributed to asthma. Fourteen (6\%) deceased persons were known to have had a physical and/or intellectual disability; five of these cases lived in residential care homes. One deceased person was in prison and unable to gain assistance during his fatal attack.

\section{Delay in seeking help}

In $73(30 \%)$ cases, the deceased person was found after death. Sixty-three $(26 \%)$ deceased persons were deemed to have delayed seeking assistance for their fatal asthma attack. In some cases, the failure to identify the seriousness of the asthma exacerbation was linked to drug and/or alcohol use. In some instances, the deceased was reported to have curled up on the couch or gone to bed feeling unwell and was later found dead. In the case of those who lived alone and were found dead, the deceased was discovered by a friend or relative or by police conducting a welfare check after referral from a concerned person.

\section{Respiratory tract infections}

In $39(16 \%)$ cases, a respiratory tract infection was reported to be present prior to the fatal asthma attack. Death certificate information between 2003 and 2007 gave an acute respiratory infection as a comorbidity in $30 \%$ of deaths, ${ }^{2}$ and therefore our figure is very likely an underestimate. Seventy-seven (32\%) cases of asthma death occurred in autumn and $63(26 \%)$ in winter.

\section{Sudden onset death/allergy/anaphylaxis}

Fatal asthma attacks were categorised as sudden onset in $111(46 \%)$ cases rather than a gradual deterioration, which has significance in that it may limit the time available to respond effectively. Specific exposures prior to onset were identified in 22(9\%) cases and included food, non-steroidal anti-inflammatory or $\beta$-blocker medication, exposure to smoke or fumes and exercise. Between 2005 and 2009, 27 deaths reported to the coroner were attributed to anaphylaxis. Although in 9 of these cases there was also a known history of asthma and allergy, as the death was coded as anaphylaxis, none of these 27 cases were included in this study.

\section{DISCUSSION}

Our retrospective study of asthma deaths between 2005 and 2009 is the most recent study of asthma deaths undertaken in Australia for nearly two decades, and the first to report asthma deaths across Australia. We revealed high specificity in the recording of asthma deaths, during examination of postmortem information and toxicology reports, to confirm that 243/283 (86\%) deaths were due to asthma rather than having asthma as a comorbidity when another immediate cause of death existed. We considered that $70 \%$ of these deaths had preventable or modifiable factors.

Although there are similarities between our findings and preventable or modifiable factors reported in earlier studies, ${ }^{3-6}$ our findings provide a greater understanding of the current circumstances surrounding asthma deaths. Previous research identified inadequate assessment or therapy, delay in seeking help, ${ }^{3} 4$ smoking, alcohol abuse, family problems ${ }^{5}$ and psychiatric disorders as factors in asthma deaths. ${ }^{6}$ In addition to these factors, our findings identify disadvantage as an underlying theme among asthma deaths in Australia and a link between inequity, psychosocial issues, health literacy and social isolation. A further concern is the higher rate of asthma deaths among those residing in rural or remote areas $(45 \%)$ given that only $32 \%$ of the overall 
Australian population live in rural or remote areas and asthma prevalence is higher in inner city areas. ${ }^{11}$ Previous population-based research has reported on the relationship between death rates and remoteness of residence between 2003 and 2007. ${ }^{2}$ In Australia, 'Medicare', a universal Government-operated public healthcare system, provides free or subsidised treatment by doctors and specialists and free treatment as a public patient in a public hospital. Despite this, equity of access to healthcare services, physical distance and poor access to health services were clearly factors in some cases that were examined; owing to the nature of our data set, however, we are unable to generalise about these findings.

The conditions in which people live and work can lead to inequities in power and resources and consequently to health inequalities. ${ }^{12}$ Although socioeconomic status and geographic location have previously been related to increased risks of death from asthma, ${ }^{13} 14$ our study confirms higher rates of asthma deaths among those living in areas of disadvantage, ${ }^{2}$ not in the workforce and/or living in rural or remote areas and among those with psychosocial issues. Two-thirds of the asthma deaths we investigated occurred in people from disadvantaged areas.

Drug and alcohol use and smoking were very high in cases of asthma death compared with the general population during the period of our investigation. A third of the cases examined used alcohol or illicit drugs prior to death compared to $9 \%$ and $13 \%$, respectively, in the general population over 14 years of age at this same time. Similarly, smoking rates were $25 \%$ compared with $17 \%$. Not all toxicology reports were available for examination electronically, and therefore actual drug and alcohol usage may be higher.

According to information in police reports and coroners' findings, the concentrations of drugs observed in asthma deaths were not all at toxic levels. Although above the legal limit of $0.05 \mathrm{~g} / 100 \mathrm{ml}$, the average blood alcohol level of $0.09 \mathrm{~g} / 100 \mathrm{ml}$ is below toxic levels. ${ }^{15}$ However, the average opiate levels, including morphine, pethidine and methadone in the group we studied, are all in excess of known toxic levels, ${ }^{15}$ indicating association of these drugs with death. It is likely that drug use, especially opiate use, to toxic levels is responsible for the failure to recognise worsening asthma and not perceiving the risk of delay in seeking treatment. Given the known pharmacological effects of these drugs on histamine release, it is possible that narcotic use is particularly problematic in the presence of asthma and physicians prescribing these drugs should be aware of this. Previous research undertaken in the USA also identified illicit drug use as a significant factor in cases of asthma deaths under 50 years of age and implied that the increase in asthma deaths in the USA may be a reflection of substance abuse and ethanol consumption. ${ }^{16}$ Our data confirm these findings.

A study investigating the involvement of $\beta_{2}$-agonists and asthma deaths also reported the presence in blood of ethanol, benzodiazepines, anti-depressants or antipsychotic medications, morphine, diazepam, codeine, methadone as well as illicit substances such as amphetamine, methamphetamine and cannabis. ${ }^{17}$ The author concluded that although alcohol probably does not precipitate asthma, sulfites present in some forms of alcohol may trigger asthma in susceptible patients. Furthermore, the use of morphine was contraindicated in conditions such as acute bronchial asthma as it may produce respiratory depression resulting in increased $\mathrm{p}_{\mathrm{a}} \mathrm{CO}_{2}{ }^{17}$

Our study identified a subset of apparently sudden onset asthma with rapid deterioration to death. Kolbe et al has previously reported that there appears to be a small proportion of people with rapid onset severe asthma who do not demonstrate usual risk factors associated with life-threatening asthma and who require different management strategies. ${ }^{18}$ The 11 deaths that occurred in public places were consistent with rapid-onset asthma attacks. Research has revealed that slow-onset asthma attacks of near fatal asthma and rapid onset attacks may have different trigger factors, with allergens a likely trigger in rapid onset and infection in slow onset attacks. ${ }^{19}$ James et al have also reported on the dichotomy of time to death and the eosinophil/neutrophil ratio in cases of asthma and of the presence of muscle shortening in short course cases $(<3 \mathrm{~h})$ and accumulation of mucus in long course cases $(>8 \mathrm{~h}) .{ }^{21}$ Mode of onset and mechanism to death vary with asthma and thus medical interventions; both acute and long term as well as more global strategies to minimise risk will need to allow for this variation.

Several deaths were very likely due to acute hypersensitivity reactions including $\beta$-blocker eye drops and nonsteroidal anti-inflammatory treatments. Our findings should alert practitioners to the possible adverse consequences of prescribing these agents in asthma and highlight the importance of an asthma action plan to advise patients to act in the event of asthma worsening.

Respiratory viral infections, recognised as the most important causes of asthma exacerbations in both children and adults, emergency department attendances ${ }^{22} 23$ and hospitalisation admissions in older people during winter $^{2}$ were a precursor to many fatal asthma exacerbations but wereoften not perceived as a risk or reason to seek asthma care. Previous research by our team that demonstrated differing perceptions of 'what constitutes an asthma attack' also added evidence that for many people, despite preventive therapy use, a respiratory viral infection may result in an asthma episode that they are 'unable to control'. ${ }^{22}{ }^{24}$ A recent study evaluating the effect of different asthma treatments on common cold-related asthma exacerbations found that severe exacerbations were reduced by budesonide/formoterol maintenance therapy and emphasised the role of inhaled corticosteroids. ${ }^{25}$

Unfamiliarity with the individual and their particular asthma needs was a factor that led to inadequate 
treatment by health professionals and carers in the hospital, the home and the institutions. This demonstrated the importance of not only continuity of care, but also tailored care. In the case of children, this may require parents and/or carers to take on a more assertive role.

Ownership of written action plans has declined, despite their being protective against asthma death ${ }^{5}$ and research reporting ownership being useful. ${ }^{23}$ In 20072008 , less than $20 \%$ of the population with asthma were reported to own one. ${ }^{2}$ Education, especially if delivered with a written asthma action plan, will assist in the recognition of asthma exacerbations, appropriate emergency asthma management and seeking care in a timely fashion. The delivery of home-based person-centred asthma self-management education utilising the recently developed patient asthma concerns tool has also proven successful in those over 50 years of age. ${ }^{26}$ Although evidence of written action plan ownership and asthma selfmanagement education was available in some cases, unfortunately this information was not available for most.

\section{Study limitations}

Our retrospective study differs from the previous mortality studies in that we used NCIS to identify asthma deaths. The limitations of our data include the examination of only those asthma deaths that were reported to the Coroner. Cases where a medical practitioner was willing to complete and sign the death certificate certifying the asthma death was not 'unexpected', 'unnatural' or 'someone in care at the time of death' were not known to us. Thus, the cases are likely to be biased towards younger people or those institutionalised at the time of death. Anticipated deaths from asthma would not have been reported, and as a consequence, our study may underestimate this group. As cause of death analysis focuses on only one underlying cause rather than multiple causes of death, the overall contribution of asthma to adult deaths in Australia is also likely to be underestimated as was found in England. ${ }^{27}$

\section{Conclusion}

Our retrospective study provides a current assessment of 'reportable' asthma deaths across Australia. Seventy per cent of these deaths were considered preventable and our findings suggest that to achieve further reductions in the rate of asthma deaths in Australia, among those aged under 70 years of age, multifaceted interventions targeted at the personal, practice and policy levels will be required.

At the personal level, improvement in asthma health literacy among those with infrequent asthma is required to identify and manage worsening symptoms and the risks associated with delay in seeking care. Parents and carers should also develop confidence to manage an attack, implement an emergency plan and to recognise when it is appropriate for them to take control if the person experiencing an asthma exacerbation fails to do so. The delivery of home-based self-management education could be appropriate to reach those who are frail, house-bound and/or socially isolated. E-health technologies should also be considered as a means of delivering education and advice to those living in areas where geographical distance is problematic.

Health professionals working in primary care settings need to ensure that all patients, not just those with moderate to severe asthma, receive comprehensive asthma education, a written Asthma Action Plan and advice about the potential risk of delay in seeking care. Quality Awards system, such as those operating in the UK, could be introduced to encourage delivery of guideline-based asthma care in Australian practices. ${ }^{28}$

At the policy level, current asthma guidelines need to highlight issues associated with asthma management in those with psychosocial problems, including drug and alcohol addiction, given that both are problematic and widespread. Provision of asthma education and a written asthma action plan should also be mandatory for those who present to emergency departments.

Interventions that specifically target community needs are also required. Reforms are needed to address inequity in healthcare delivery to 'reach the unreached' as well as raising the awareness of dangers associated with smoking, drug and alcohol use and the consequences of delay in seeking care for those with asthma. A recent method of engaging communities has been the use of performance ${ }^{29}$ to raise awareness and deliver health messages. These plays can be performed in a variety of settings, including schools, pubs, seniors clubs and conferences. The recently introduced Medicare Local network in Australia is very likely a place to determine a need.

\section{Future research}

A case control study of asthma deaths in Australia is required. It should investigate deaths across all age groups, the circumstances surrounding the death as well as the management of fatal attacks and the quality of care in the preceding 12 months such as that currently being undertaken in the UK. ${ }^{30}$

\section{Author affiliations}

${ }^{1}$ RDNS Institute, Royal District Nursing Service, St Kilda \& Central Clinical School, Monash University, Melbourne, Victoria, Australia

2Department of Epidemiology and Preventive Medicine, Monash University, School of Public Health \& Preventive Medicine, The Alfred, Melbourne, Victoria, Australia

${ }^{3}$ Department of Allergy, Immunology and Respiratory Medicine (AIRmed), The Alfred Hospital and Monash University, Melbourne, Victoria, Australia ${ }^{4}$ Department of Clinical Immunology and Allergy, Royal Melbourne Hospital, University of Melbourne, Parkville, Victoria, Australia

Acknowledgements The authors would like to acknowledge Joanna Cotsonis from the Department of Justice and Michele Bayley-Jones and Annemarie Van Putten from the South Australian Coroner's Office for their assistance in accessing case data.

Contributors DG and JD conceived the idea of the study. DG, JD and MA were responsible for the design of the study. DG, EM, JD, CZ and MA were responsible for undertaking the data analysis. DG and EM produced the tables 
and graphs. The initial draft of the manuscript was prepared by DG and then circulated repeatedly among all authors for critical revision. DG was responsible for the acquisition of the data and all authors contributed to the interpretation of the results. All authors approved the final version for publication.

Funding This research was funded from a Helen Macpherson Smith Grant provided by the Asthma Foundation of Victoria.

Competing interests None.

Ethics approval The Alfred Hospital Human Research and The Department of Justice Ethics Committees.

Provenance and peer review Not commissioned; externally peer reviewed.

Data sharing statement No additional data are available.

\section{REFERENCES}

1. Australian Bureau of Statistics (ABS) 2013. Causes of deathAustralia 2011. Canberra, Australia: ABS.

2. Australian Centre for Asthma Monitoring (ACAM) 2011 Asthma in Australia 2011. AlHW Asthma Series no 4. Cat. No. ACM22. Canberra: AlHW.

3. Robertson C, Rubinfeld A, Bowes G. Deaths from asthma in Victoria: a 12 month survey. Med $J$ Aust 1990;152:511-17.

4. Robertson C, Rubinfeld A, Bowes G. Pediatric asthma deaths in Victoria: the mild are at risk. Pediatr Pulmonol 1992;13:95-100.

5. Abramson M, Bailey M, Couper F, et al. Are asthma medications and management related to deaths from asthma? Am J Respir Crit Care Med 2001;163:12-18.

6. Campbell D, McLennan G, Coates J, et al. A comparison of asthma deaths and near-fatal asthma attacks in South Australia. Eur Respir J 1994;7:490-7.

7. Australian Institute of Health and Welfare (AIHW) 2011. General Record of Incidence of Mortality (GRIM) Books. Canberra: AlHW.

8. National Coroners Information System (NCIS). NCIS Version 5.2, released April 2011. Southbank, Victoria, Australia: Victorian Institute of Forensic Medicine.

9. World Health Organisation (WHO) International Classification of Diseases 2010.

10. Australian Bureau of Statistics (ABS). 2033.0.55.001 Socio-economic Indexes for Areas (SEIFA), released on the 26th March 2008 (Canberra).

11. Australian Institute of Health and Welfare 2008. Australia's health 2008. Cat. no. AUS 99. Canberra: AlHW.

12. Marmot M, Allen J, Bloomer E, et al. WHO European review of social determinants of health and health divide. Lancet 2012;380:1011-29.
13. Castro M, Schechtman K, Halstead J, et al. Risk factors for asthma morbidity and mortality in a large metropolitan city. $J$ Asthma 2001;38:625-35.

14. Dunn C, Sadkowsky K, Jeffs P. Trends in deaths: Australian data, 1987-1998 with updates to 2000. Mortality surveillance series no 3. Cat No. PHE 40. Canberra: AlHW, 2002.

15. Schulz M, Iwesen-Bergmann $\mathrm{S}$, Andresen $\mathrm{H}$, et al. Therapeutic and toxic blood concentrations of nearly 1000 drugs and other xenobiotics. Crit Care 2012;16:R136.

16. Krantz A, Hershaw R, Prachand N, et al. Heroin insufflations as a trigger for patients with life-threatening asthma. Chest 2003;123:510-17.

17. Couper $\mathrm{F}$. The involvement of $\beta 2$-agonists in asthma deaths. [Doctoral Thesis]. Southbank, Victoria: Monash University, Department of Forensic Medicine, 1997.

18. Kolbe J, Ferguson W, Garrett J. Rapid Onset asthma: a severe but uncommon manifestation. Thorax 1998;53:241-7.

19. Rodrigo G, Rodrigo C. Rapid Onset asthma attack: a prospective cohort study about characteristics and response to emergency department treatment. Chest 2000;118:1547-52.

20. Plaza V, Serrano J, Pacado C, et al. Frequency and clinica characteristics of rapid-onset fatal and near fatal asthma. Eur Respir J 2002;19:846-52.

21. James A, Elliot J, Abramson M, et al. Time to death, airway wall inflammation and remodelling in fatal asthma. Eur Respir $J$ 2005;26:429-34.

22. Reddel H, Ware S, Marks G, et al. Differences between asthma exacerbations and poor asthma control. Lancet 1999;353:364-9.

23. Goeman D, Aroni R, Sawyer S, et al. Back for more: a qualitative study of emergency department re-attendance for asthma. Med Aust 2004;180:113-17.

24. Aroni R, Goeman D, Stewart K, et al. Enhancing validity: what counts as an asthma attack? J Asthma 2004;41:729-37.

25. Reddel H, Jenkins C, Quirce S, et al. Effect of different asthma treatments on risk of cold-related exacerbations. Eur Respir $J$ 2011;38:584-93.

26. Goeman D, Jenkins C, Crane M, et al. An educational intervention for older people with asthma: a randomised controlled trial. Respirology 2012;17(S1):18.

27. Goldacre M, Duncan M, Griffith M. Death rates for asthma in English populations 1979-2007: comparison of underlying cause and all certified causes. Public Health 2012;126:386-93.

28. Primary Care Respiratory Society-UK Quality Award.http://www. pcrs-uk.org/quality award/standards.php (accessed Jun 2012).

29. Jones K. Connecting research with communities through performative social science. Qual Rep 2012;17:1-8.

30. Levy M. Obtaining outcome data on asthma management: the UK National Review of Asthma Deaths. Prim Care Respir $J$ 2012;21:18. 